\title{
Multi String Grid-Connected PV System with LLC Resonant DC/DC Converter
}

\author{
Concettina Buccella $^{1,2}$ - Carlo Cecati $^{1,2}$ - Hamed Latafat ${ }^{1,2}$ - Kaveh Razi ${ }^{1,2}$
}

Received: 24 January 2015 / Revised: 12 March 2015 / Accepted: 12 March 2015 / Published online: 28 May 2015

(C) Springer Science+Business Media Singapore 2015

\begin{abstract}
This paper presents a grid-connected multi string photovoltaic (PV) system with a three level voltage source converter using double closed loop control strategy. The outer DC voltage control loop regulates the DC bus voltage while the inner current control loop synchronizes the output current with the grid voltage, thus ensuring unity power factor. In the proposed configuration, LLC resonant DC/DC converter is used to extract the maximum power and to boost the PV array voltage. It is intrinsically isolated by a high frequency transformer, so that the parasitic capacitance of the PV panels to ground could not be of concern; furthermore, because of soft switching technique, LLC converter operates at high frequency with low switching losses. Size and cost of the magnetic components and DC-link capacitor are decreased compared with traditional boost converters. An incremental conductance method integrated with PI controller is developed on LLC resonant converter to extract maximum power. Simulation studies confirm that the control design approaches taken are robust and the dynamic performance of the proposed system during fast solar irradiation changes is acceptable.
\end{abstract}

Keywords Photovoltaic (PV) systems - Maximum power point tracking (MPPT) · Grid-connected · LLC resonant converter $\cdot$ Grid synchronization

Carlo Cecati

carlo.cecati@univaq.it

1 Department of Information Engineering, Computer Science and Mathematics, University of L'Aquila, Via Vetoio, 67100 L'Aquila, Italy

2 DigiPower s.r.1., Via Monte Velino 29, 67100 L'Aquila, Italy

\section{Introduction}

Photovoltaic (PV) generation systems consist of PV panels and a number of auxiliary parts necessary to adapt the produced energy in a form easily available to common loads such as home appliances, industrial loads and many others. The currently used PV systems are generally configured in two main structures, stand-alone [1,2] and grid-connected [3-7], in a wide power range from few watts up to several MWs. First case usually requires an electric energy storage unit to store the captured energy while it isn't used releasing the energy when needed. This structure uses simple power converters such as battery charger and a very simple and low cost DC/AC inverter which can supply both DC and AC loads [8-12]. The main drawback of standalone structure is that the maximum available power isn't always used, while maximum power point tracking (MPPT) control could be accomplished [13]. The grid-connected PV systems can transfer all of maximum available PV energy to the loads and/or grid simultaneously without any energy storage necessity. The injected energy in grid-connected systems at the point of common coupling, has low current and voltage harmonics [14]. However, this structure requires more complex converter and control schemes such as active and reactive power control, voltage and current control, synchronization, and power quality control [15].

The efficiency of the system depends on the capability of the inverter to extract the maximum available power from the PV arrays in real time and force the PV system to operate at that maximum power point (MPP). A large number of MPPT techniques together with their implementation methods are reported in the literature such as perturb and observe [16-18], incremental conductance ( $\mathrm{InC})$ [19,20], ripple correlation control [21], one-cycle control [22,23], Intelligent MPPT Techniques [24,25], distributed MPPT [26], current- 
Fig. 1 Configuration of typical three-phase grid-connected

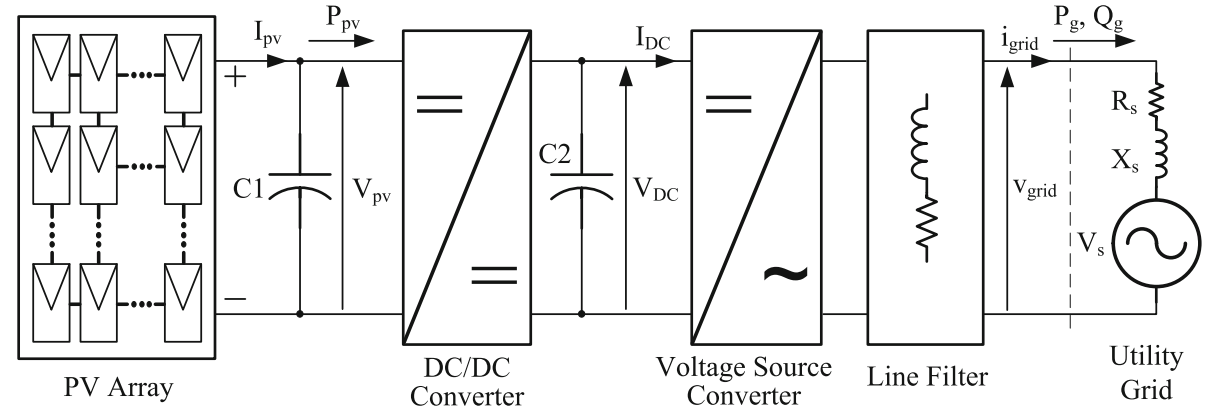

based sliding mode control technique [27,28], etc. These algorithms could be easily designed and implemented using a digital signal processor or a field programmable gate array [29]. A dual stage grid-connected PV system shown in Fig. 1 has been widely used due to the simple control and independent operation. It consists of arrays of PV panels, a DC/DC converter, a voltage source converter (VSC) and a line filter. Isolation between the input and output powers could be achieved through a DC/DC converter or by using an isolation transformer after the VSC [30]. The control system includes inner current and outer voltage loops, the latter ensuring a tight regulation of the DC-link voltage, needed to generate the amplitude of the reference current. The inner current loop usually uses a reference current in order to synchronize the output current of the inverter with the grid voltage thus ensuring unity Power Factor (PF) [31-34]. Conventionally, a boost DC/DC converter is being used for boosting the voltage of PV panels up to the desired DC-link level and also for extracting the MPP of the PV panels. In this kind of converters, since the switching of semiconductor devices occurs at high currents, efficiency of them at high frequencies is low because of the hard switching losses. In the other hand, at low frequencies the size and cost of the magnetic components and the link capacitor would be high to maintain the DC-link voltage ripple in acceptable operating range. Furthermore, the parasitic capacitance of the PV panels to ground could cause leakage currents due to lack of isolation $[35,36]$.

To overcome these problems, a full bridge LLC resonant $\mathrm{DC} / \mathrm{DC}$ converter is proposed in this paper to connect the PV array to the grid. By using the proposed converter, softswitching operation as well as high frequency switching can be achieved and the size of magnetic and filter components can be greatly reduced which consequently results in lower electromagnetic interferences (EMI). Also, the LLC resonant DC/DC converter provides electrical isolation that avoids leakage currents problem which exists by using boost DC/DC converter. Furthermore, the DC-link capacitor used to store energy and act as a fixed DC bus for the inverter could be selected smaller in comparison with typical boost converter $[37,38]$. This approach was introduced in the previous work [39] only for one PV array. In this paper a large PV system with multi-string structure is studied and developed, and an
InC based method integrated with proportional-integral (PI) controller is proposed by LLC resonant DC/DC converter as MPPT controller [40,41]. As the result, the total performance of the PV system has been improved. In the following sections, a dual string PV system with central VSC topology has been considered and the simulation studies have been presented to validate the response of the system to sudden changes of solar irradiation. The proposed structure, which utilizes the LLC resonant converter with standalone MPPT controller for each string, has also a modular structure. Hence, the PV system can be easily extended to higher number of the strings just by paralleling the outputs of the LLC resonant DC/DC converters. But, in the case of using conventional boost DC/DC converters, interleaved structure and power distribution control must be used for expansion of the PV system.

In "PV Array and MPPT Algorithm" section the mathematical model of a PV module and its characteristics including P-V curves of studied PV arrays and MPPT algorithm are presented, in "LLC Resonant DC/DC Converter" section the LLC resonant DC/DC converter and its operation are described; "Voltage Source Converter" section describes the VSC interface with the grid and its voltage and current control loops. In "Simulation Results" section, simulation results demonstrate the quality of the achievable results and finally, "Conclusions" section draws some conclusions.

\section{PV Array and MPPT Algorithm}

PV modules can be modeled using a current source controlled by voltage, which depends on temperature and solar irradiation power. According to [42], the mathematical equation for the model is:

$I=I_{p v}-I_{0}\left[\exp \left(\frac{q\left(V+R_{s} I\right)}{N_{s} K T a}\right)-1\right]-\frac{V+R_{s} I}{R_{s h}}$,

where $I_{p v}$ and $I_{0}$ are the PV and the diode saturation currents, respectively. $N_{S}$ is the number of series-connected cells, $k$ is 
the Boltzmann constant ${ }^{1}, T$ (Kelvin) is the temperature of the $\mathrm{p}-\mathrm{n}$ junction of the diode, and $q^{2}$ is the electron charge. $R_{s}$ and $R_{s h}$ are the equivalent series and shunt resistances of the module, and $a$ is the diode constant factor $(1 \leq a \leq 1.5)$.

For modeling of the simulated arrays, the SunPower SPR305E-WHT (305W) PV modules are used in this study [43]. Fig. 2 shows characteristic curves of each simulated PV module for different irradiance levels with constant ambient temperature of $25^{\circ} \mathrm{C}$. Also, the characteristics of two PV arrays which are used in this study, are shown in Fig. 2 at the same condition. The voltage, current and available power at maximum power point (MPP) are also shown in the figures.

Since the extracted maximum power from PV array is continuously changing due to ambient temperature and the solar irradiance variations, a MPPT algorithm is necessary to track the maximum power. Among the already cited MPPT algorithms, performance of the InC method under rapid solar variations is quite satisfactory [44]. This method has a better performance in both transients and steady states conditions [40] and has been developed on LLC resonant DC/DC converters.

So, for deriving the output power $P=V I$, regarding the output voltage we could consider Eqs. (2) and (3).

$$
\begin{aligned}
& \frac{d P}{d V}=\frac{d(V I)}{d V}=I+V \frac{d I}{d V} \\
& \frac{d P}{d V}=0 \Longrightarrow \frac{d I}{d V}=-\frac{I}{V}
\end{aligned}
$$

To minimize the error, a PI controller has also been integrated with this method as depicted in Fig. 3. The Inc algorithm is based on the fact that at MPP, the derivative of the output power with respect to output voltage of the PV array is zero. This derivative is positive on the left side of the MPP and negative on the right side of the MPP as shown in Fig. 2.

The proportional integral (PI) controller minimizes the error $(d I / d V+I / V)$ and its output passes through the voltage controlled oscillator. This is because in LLC resonant converter, the controller stabilizes the output by changing the switching frequency rather than the duty cycle.

By considering the DC-link voltage to be fixed by VSC, it is possible to get desired power from PV array by changing the voltage gain of the LLC resonant converter. This could be done by varying the equivalent input resistance of the converter. When the solar irradiation changes, the MPPT controller increases or decreases the converter gain regardingly, in order to reach the new MPP. The inputs for the MPPT controller are the voltage and current of the PV array, and the

\footnotetext{
${ }^{1} k=\left(1.3806503 \times 10^{-23} \mathrm{~J} / \mathrm{K}\right)$.

${ }^{2} q=1.60217646 \times 10^{-19} \mathrm{C}$.
}

outputs are the gate signals of the DC/DC converter switches as shown in Fig. 3.

\section{LLC Resonant DC/DC Converter}

Resonant full bridge LLC converter circuit configuration is shown in Fig. 4. MOSFET power switches are configured to generate a bipolar square-wave voltage and should be able to work at high frequencies. Notice that a small dead-time is required between two consecutive transitions to prevent cross-conduction and to allow time for zero voltage switching (ZVS) to be achieved.

The resonant circuit consists of the series resonant capacitor $\left(C_{r}\right)$, the series resonant inductance $\left(L_{r}\right)$, transformer magnetizing inductance $\left(L_{m}\right)$. It circulates the electric current so that the energy is delivered to the load through a step-up transformer supplied by a square-wave voltage providing both the electrical isolation and amplitude boost, up to the required output level. A full-wave rectifier on the converter secondary side converts the $\mathrm{AC}$ input to the desired value of the DC bus.

The resonant LLC tank voltage and current waveforms of the converter at a frequency lower than resonance frequency is shown in Fig. 5. As shown in this figure, ZVS is achieved by flowing the magnetizing current of $L_{m}$ through reverse body diode and this current should be large enough to ensure ZVS in all operation ranges of converter by taking into account the dead-band time $[37,45,46]$. The energy amount to be delivered to the DC bus is mainly depend on the value of the resonant circuit impedance at certain frequency for a given load impedance. As the frequency of the square-wave changes, the resonant tank impedance varies to control the delivered energy.

This circuit presents two different resonance frequencies:

$$
\begin{aligned}
& f_{r 1}=\frac{1}{2 \pi \sqrt{L_{r} C_{r}}} \\
& f_{r 2}=\frac{1}{2 \pi \sqrt{\left(L_{r}+L_{m}\right) C_{r}}} .
\end{aligned}
$$

For LLC circuit design, the fundamental harmonic approximation (FHA) method has been used [47]. This method produces satisfactory results while operating close to the resonance frequency $f_{r 1}$. In this method, only fundamental components of voltage and current are considered. The FHA method can be used to find the DC voltage gain, or the voltage transfer function.

The AC equivalent load resistance, $\left(R_{e q}\right)$ can be calculated as follows $[45,46]$ :

$R_{e q}=\frac{8}{\pi^{2}} R_{o}$ 
Fig. 2 V-I and P-V

characteristics of simulated PV system
Fig. 3 Block diagram of the MPPT controller using InC method
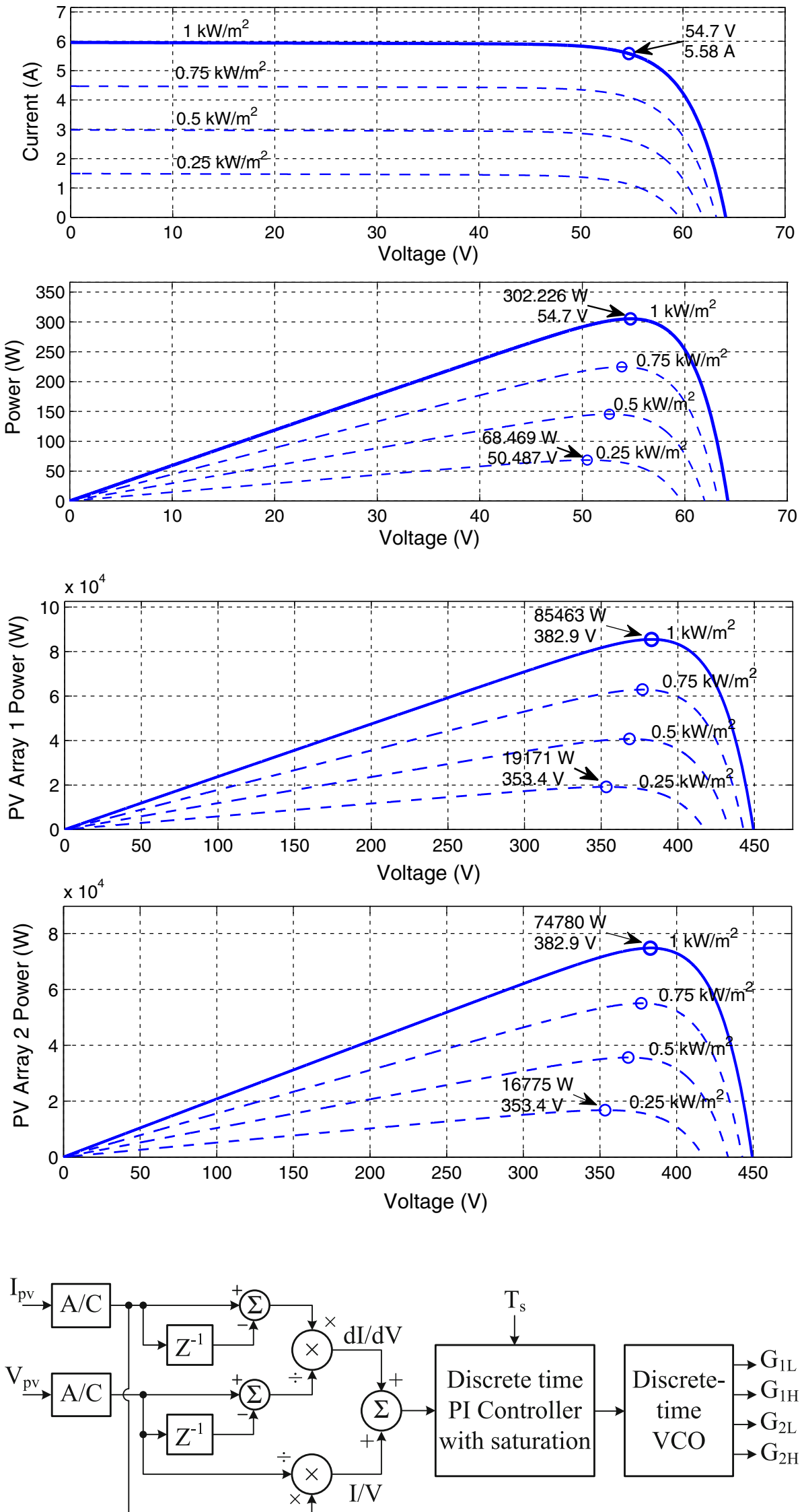
Fig. 4 Full bridge DC/DC LLC resonant converter with MPPT controller

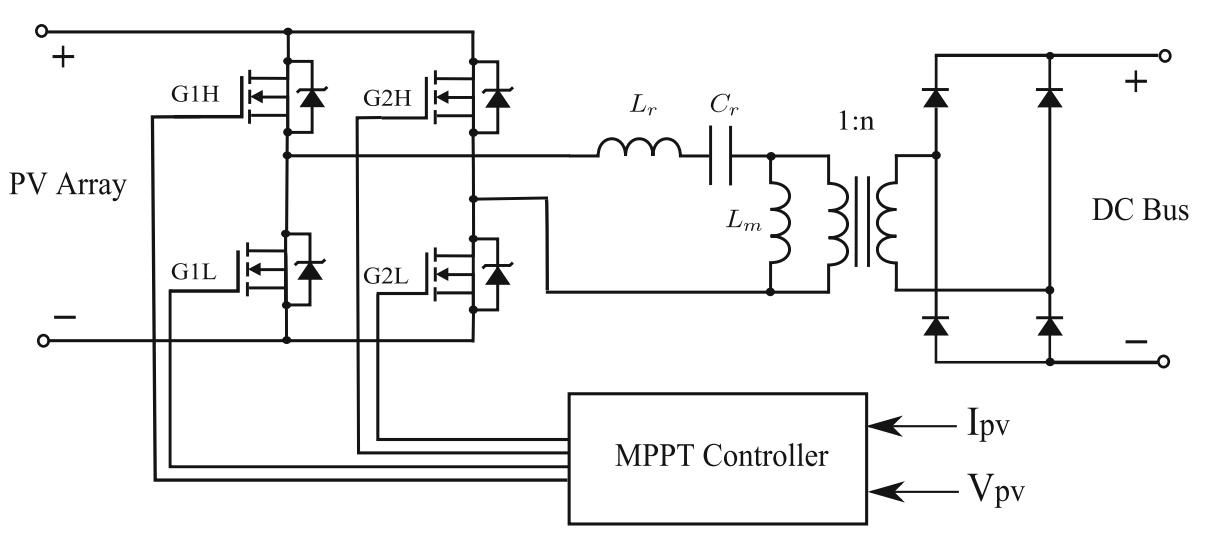

Fig. 5 Resonant LLC tank voltage and current at frequency below $f_{r}(\mathrm{CH} 1: 50 \mathrm{~V} /$ div, $\mathrm{CH} 2$ : 10 A/div, Time: $2 \mu \mathrm{s} / \mathrm{div}$ )

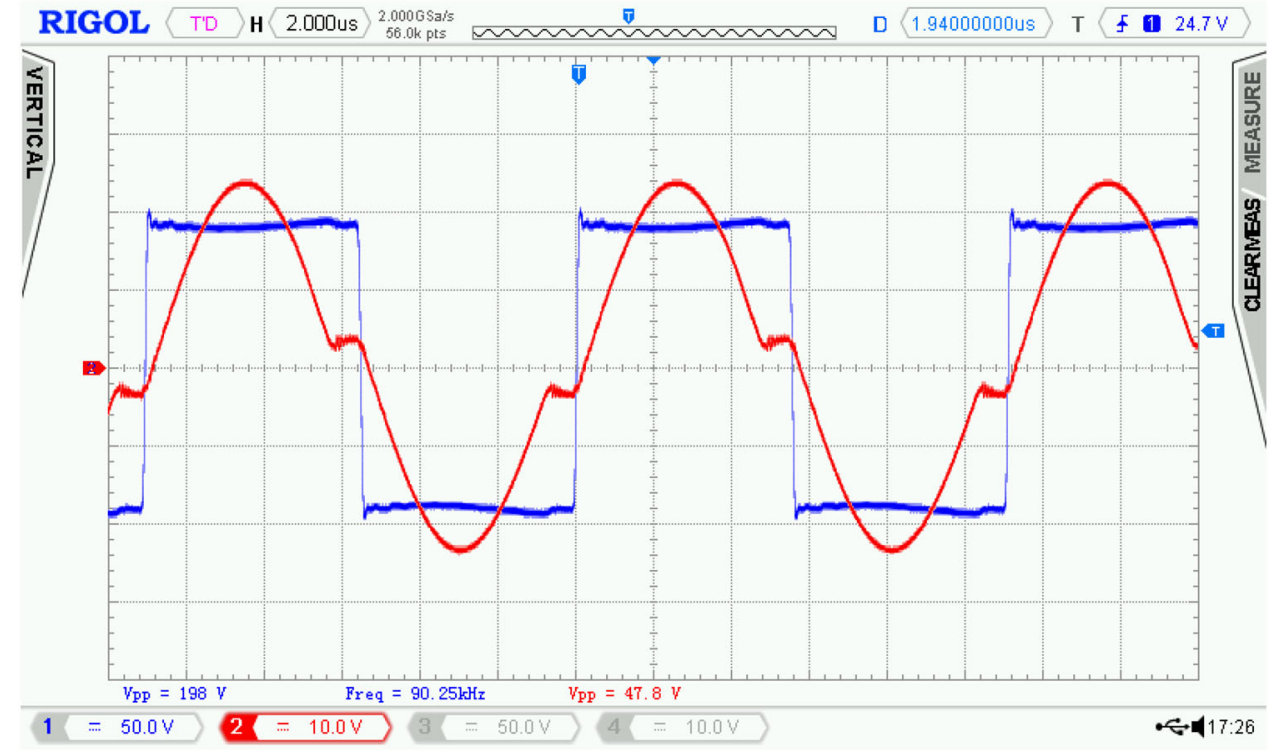

where $R_{o}$ is the actual DC side load resistance. Quality factor $(Q)$ of the circuit could be defined as:

$Q=\frac{1}{R_{e q}} \sqrt{\frac{L_{r}}{C_{r}}}$.

The relationship between DC voltage gain of the LLC resonant converter with normalized switching frequency could be expressed as:

$M=\left|\frac{L_{n} f_{n}^{2}}{\left[\left(L_{n}+1\right) f_{n}^{2}-1\right]+j\left[\left(f_{n}^{2}-1\right) f_{n} Q L_{n}\right]}\right|$,

where the inductance ratio $L_{n}$ and normalized switching frequency $f_{n}$ are defined in (9) and (10).

$$
\begin{aligned}
L_{n} & =\frac{L_{r}}{L_{m}} \\
f_{n} & =\frac{f_{\text {switch }}}{f_{r 1}} .
\end{aligned}
$$

The Eq. (8) is plotted in Fig. 6 for different $Q$ values with respect to switching frequency. At frequencies higher than $f_{r 1}$, ZVS operation of the primary switches and zero current switching operation of the rectifier diodes are ensured.

The MPPT algorithm used for this converter is the incremental conductance integrated with PI controller which has been discussed in "PV Array and MPPT Algorithm" section and has shown in Fig. 3.

\section{Voltage Source Converter}

The grid side inverter used in this work is a three level neutral point clamped VSC that is made of insulated gate bipolar transistor (IGBT) switches. The rated apparent power capacity is $200 \mathrm{kVA}$, the VSC converts the $750 \mathrm{~V}$ DC voltage to $400 \mathrm{~V}$ AC line voltage which its switching frequency is $3 \mathrm{kHz}$.

The adopted control strategy consists of two cascaded loops: internal current loop for grid synchronization and external voltage loop to regulate the DC bus voltage. 
Fig. 6 Voltage gain of LLC resonant converter versus switching frequency

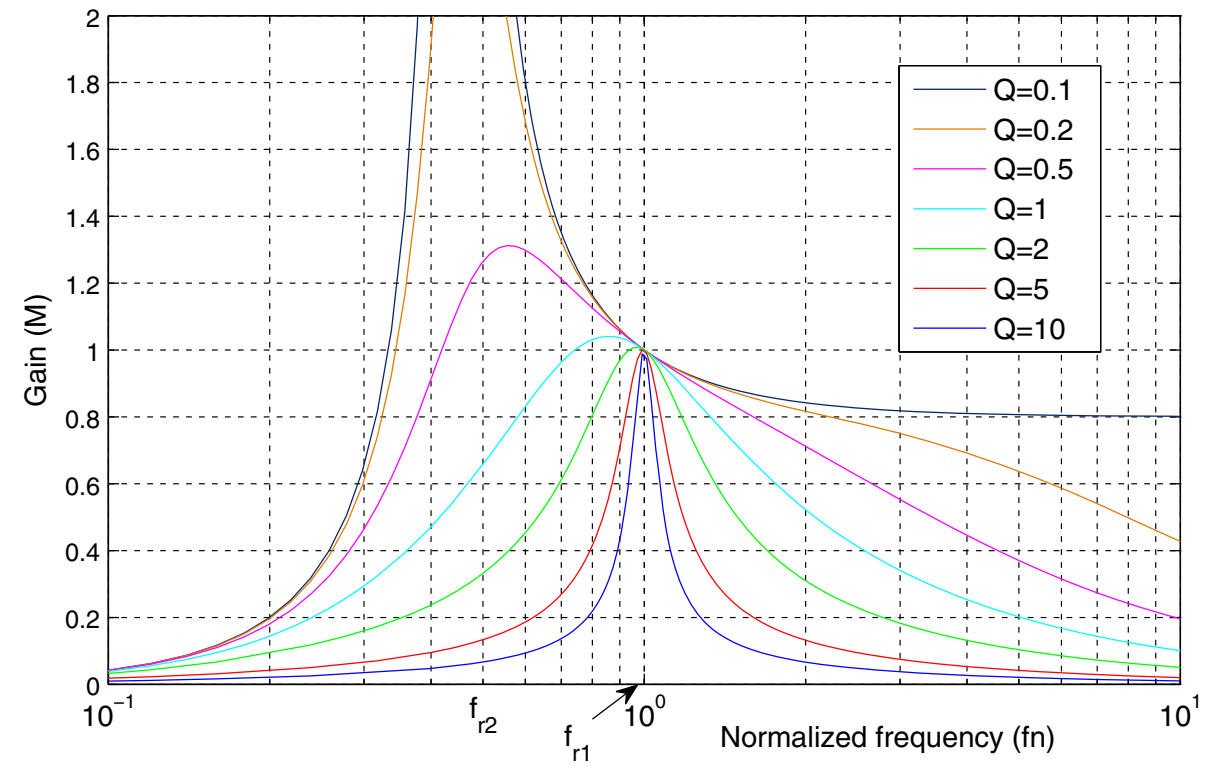

Fig. 7 Block diagram of the control strategy applied to the VSC

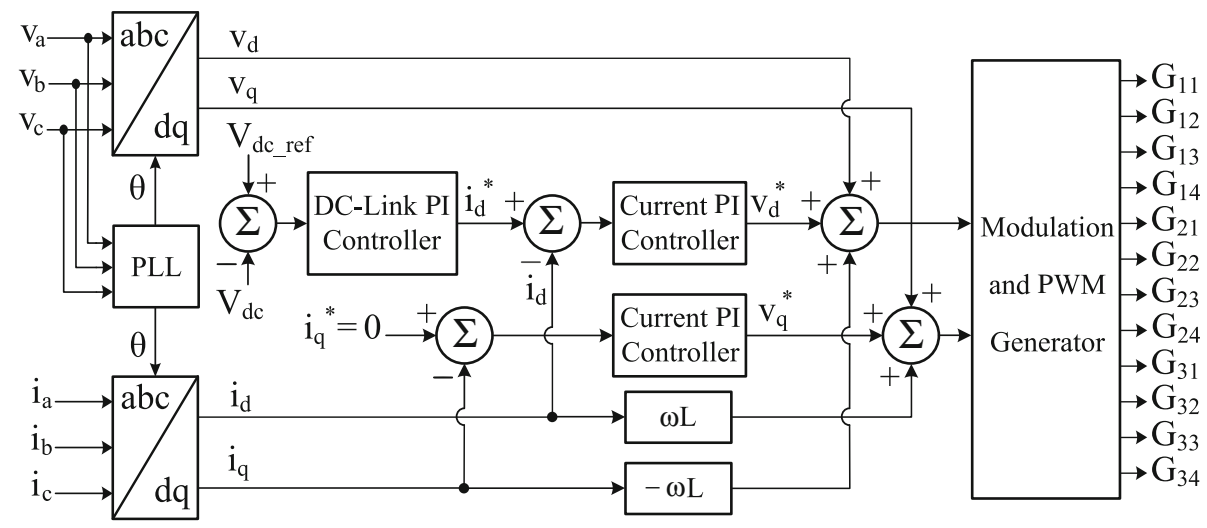

\section{DC-Link Voltage Controller}

The controller regulates the DC bus voltage at $750 \mathrm{~V}$ reference voltage regarding the desired active power. Fig. 7 shows the block diagram of the controller. As it can be seen from this figure, the output of the controller is used as the reference for the active current controller.

\section{Internal Current Loop}

A synchronous reference frame control (or $d-q$ control using $a b c \rightarrow d q$ transformation) [30] has been adopted and is shown Fig. 7. A phase-locked loop technique extracts the phase angle used in the $a b c \rightarrow d q$ transformation, thus synchronizing the controlled current with the grid voltage. Since the reactive power control is not studied in this paper, the reference for the reactive current $I_{q}$ is set to zero in order to maintain unity power factor. The reference for active current $I_{d}$ comes from the DC-link voltage controller as discussed in the previous subsection. For the implementation of the con- trol scheme, the grid-connected system shown in Fig. 8 is considered.

In the proposed control scheme, voltage outputs of the current controller are converted into three modulating signals used by the three-level PWM pulse modulator. The PI controllers are used in this structure.

\section{Simulation Results}

The proposed system is shown in Fig. 8. Passive elements, $C_{1}$, $C_{2}, C_{3}, C_{4}, L_{1}$ and $L_{2}$, were used to filter the high frequency currents sinked by LLC resonant converter and smoothing the output voltage and current of each PV array. $C_{5}$ and $C_{6}$ are DC-link capacitors for three level VSC. A $10 \mathrm{kVAR}$ capacitor bank is used to filter the harmonics produced by VSC. All of the control blocks were discussed in previous sections. The entire PV system model was implemented and simulated using Matlab/Simulink software [48]. 


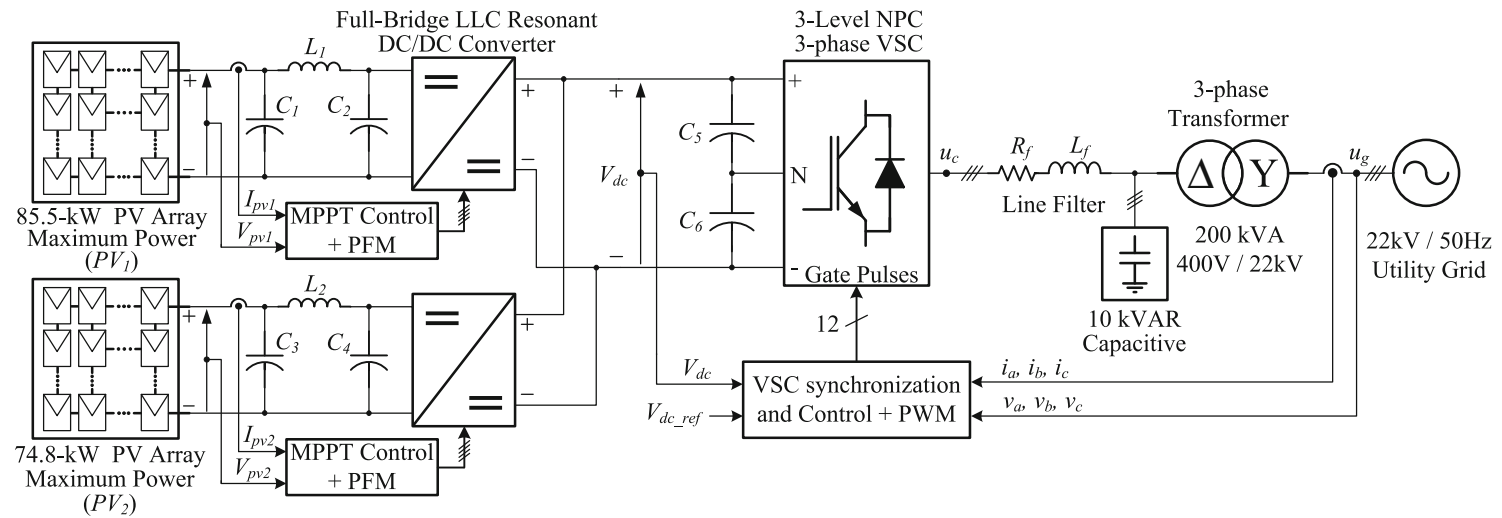

Fig. 8 Block diagram of the proposed multi string PV plant connected to MV grid

Table 1 PV arrays specifications under STC

\begin{tabular}{|c|c|}
\hline Parameter & Value \\
\hline Module open-circuit voltage $\left(\mathrm{V}_{\mathrm{oc}}\right)$ & $64.2 \mathrm{~V}$ \\
\hline Module short-circuit current $\left(\mathrm{I}_{\mathrm{oc}}\right)$ & $5.96 \mathrm{~A}$ \\
\hline Module voltage at maximum power point $\left(\mathrm{V}_{\mathrm{mp}}\right)$ & $54.7 \mathrm{~V}$ \\
\hline Module current at maximum power point $\left(\mathrm{I}_{\mathrm{mp}}\right)$ & $5.58 \mathrm{~A}$ \\
\hline Number of series-connected modules per string & 7 \\
\hline Number of parallel strings of $\mathrm{PV}_{1} / \mathrm{PV}_{2}$ & $40 / 35$ \\
\hline $\mathrm{PV}_{1} / \mathrm{PV}_{2}$ arrays max. power at $1000 \mathrm{~W} / \mathrm{m}^{2}\left(\mathrm{P}_{\mathrm{mp}}\right)$ & $85.5 / 74.8 \mathrm{~kW}$ \\
\hline $\mathrm{PV}_{1}$ and $\mathrm{PV} V_{2}$ arrays voltage at $\mathrm{MPP}$ at $1000 \mathrm{~W} / \mathrm{m}^{2}$ & $382.9 \mathrm{~V}$ \\
\hline $\mathrm{PV}_{1} / \mathrm{PV}_{2}$ arrays maximum power at $250 \mathrm{~W} / \mathrm{m}^{2}$ & $19.2 / 16.8 \mathrm{~kW}$ \\
\hline $\mathrm{PV}_{1}$ and $\mathrm{PV} V_{2}$ arrays voltage at MPP at $250 \mathrm{~W} / \mathrm{m}^{2}$ & $353.4 \mathrm{~V}$ \\
\hline
\end{tabular}

Table 2 grid-connected PV plant system parameters

\begin{tabular}{ll}
\hline Parameter & Value \\
\hline $\mathrm{C}_{1}, \mathrm{C}_{2}, \mathrm{C}_{3}, \mathrm{C}_{4}[\mu \mathrm{F}]$ & 1500 \\
$\mathrm{~L}_{1}, \mathrm{~L}_{2}[\mu \mathrm{H}]$ & 0.01 \\
$\mathrm{C}_{5}, \mathrm{C}_{6}[\mu \mathrm{F}]$ & 3000 \\
$\mathrm{R}_{f}[\mathrm{~m} \Omega] / \mathrm{L}_{f}[\mu \mathrm{H}]$ & $3 / 750$ \\
$\mathrm{DC} / \mathrm{DC}$ converter resonance frequency $[\mathrm{kHz}]$ & 100 \\
3 -level VSC switching frequency [kHz] & 3 \\
DC link refrence voltage [V] & 750 \\
Transformer resistance [p.u.]/leakage reactance [p.u.] & $0.001 / 0.03$ \\
Transformer primary [kV]/secondary voltage [V] & $22 / 400$ \\
Grid nominal line voltage [kV]/frequency [Hz] & $22 / 50$ \\
Transformer nominal power [kVA]/Base power[kVA] & $200 / 100$ \\
\hline
\end{tabular}

Specifications of the PV modules and arrays under standard test condition (STC; irradiance $=1000 \mathrm{~W} / \mathrm{m}^{2}$, temperature $=25{ }^{\circ} \mathrm{C}$ ) are given in Table 1 . The grid parameters, filters, DC-link voltage, and other system parameters are represented in Table 2. All of the proportional and integral constants of the PI controllers were tuned by trial-anderror starting with initial values obtained by Ziegler-Nichols method.
To test the performances of the MPPT control algorithm applied to LLC resonant converter and demonstrate the grid synchronization and DC bus voltage regulation of the VSC, ramp and step changes in solar irradiation were considered and are shown in Figs. 9 and 10. In this regard irradiation was varied from 1000 to $250 \mathrm{~W} / \mathrm{m}^{2}$ and returns back to the primary value after some ramp and step changes. 
Fig. 9 System parameters $\mathrm{P}_{\mathrm{pv} 1}$, $\mathrm{P}_{p v 2}, \mathrm{P}_{G r i d}, \mathrm{~V}_{p v 1}, \mathrm{~V}_{p v 2}$ and $\mathrm{V}_{d c}$ responses versus MPPT activation and irradiation ramp down change
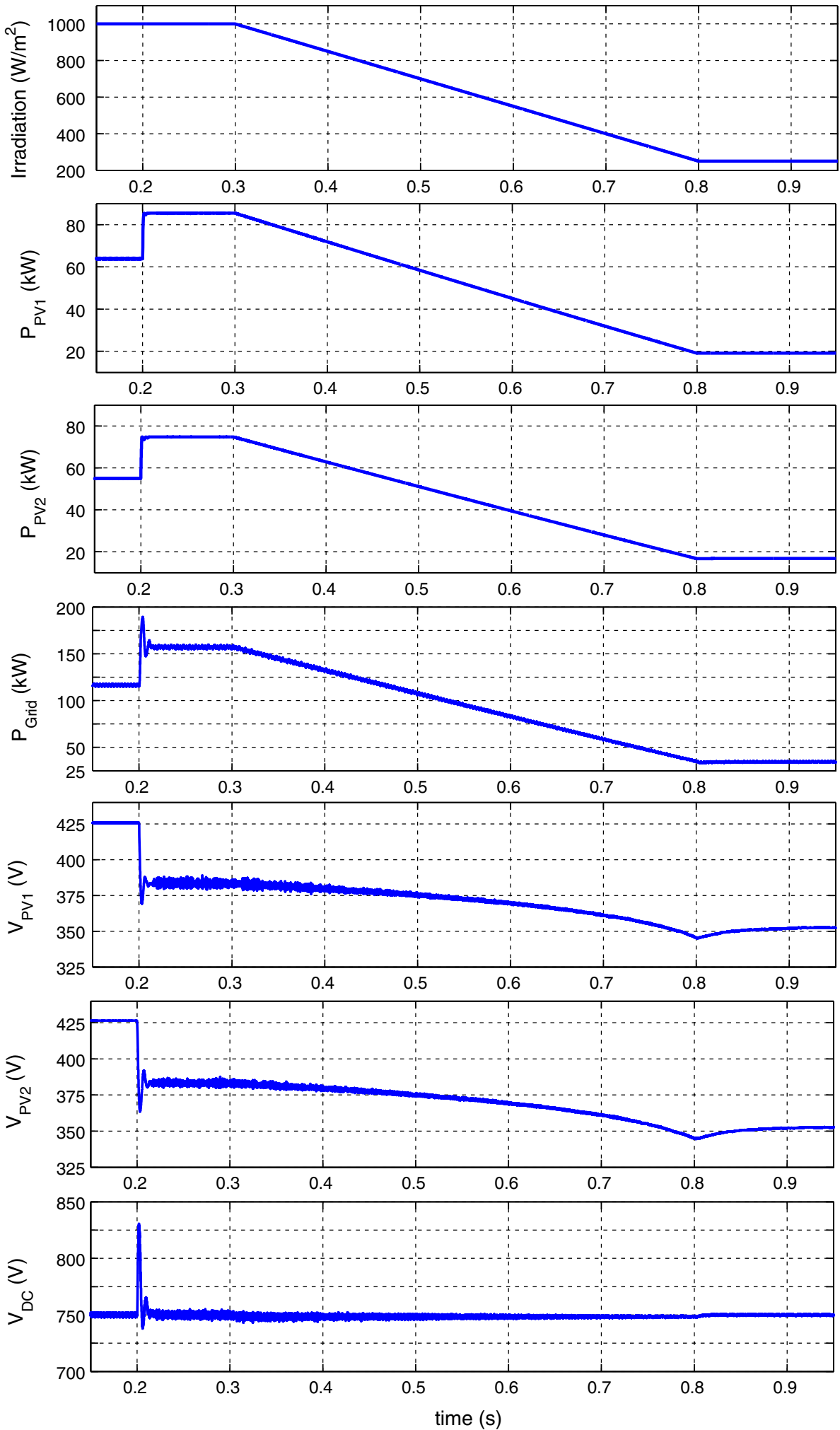

At first, the sun irradiance was set to $1000 \mathrm{~W} / \mathrm{m}^{2}$ and the MPPT controller was disabled and the initial amount of power $(117.5 \mathrm{~kW})$ was transferred to the grid by DC/DC and VSC converters. At $t=0.2 \mathrm{~s}$ the MPPT controller was enabled and starts regulating the voltage gain of the resonant DC/DC converter by changing the switching frequency in order to extract maximum power. 
Fig. 10 System parameters $\mathrm{P}_{p v 1}, \mathrm{P}_{p v 2}, \mathrm{P}_{\text {Grid }}, \mathrm{V}_{p v 1}, \mathrm{~V}_{p v 2}$ and $\mathrm{V}_{d c}$ responses versus irradiation ramp up and step changes
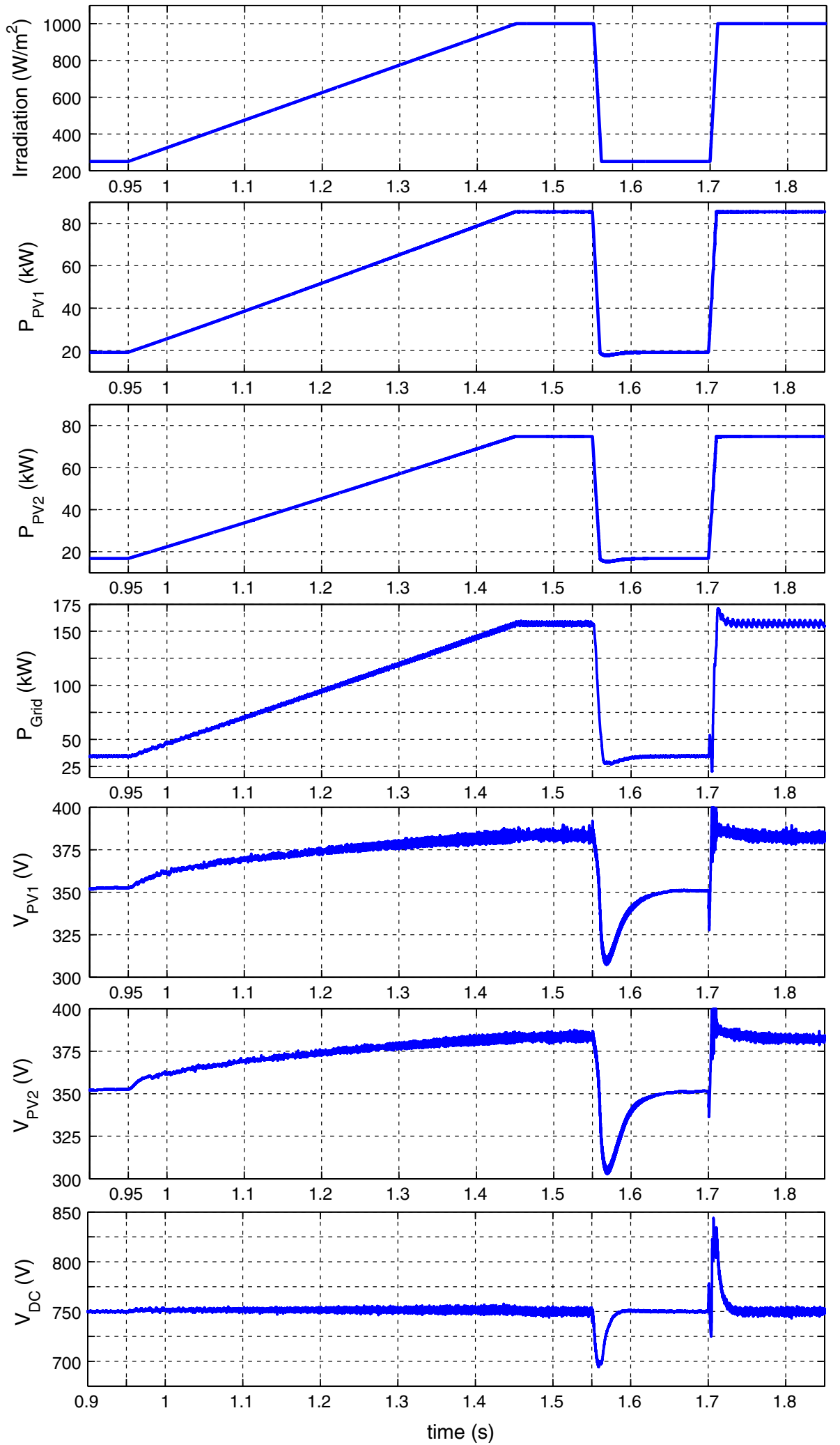

PV system power and injected power to grid were arrived at steady state in about 2 and 10 milliseconds, respectively. At the steady state, $P_{p v 1}=85.45 \mathrm{~kW}, P_{p v 2}=74.78 \mathrm{~kW}$,
$P_{\text {out }}=157 \mathrm{~kW}, V_{p v 1}=383.5 \mathrm{~V}$ and $V_{p v 2}=383.5 \mathrm{~V}$ were achieved as expected from PV arrays specifications and the efficiency of $\eta=98 \%$ was obtained. At $t=0.3 \mathrm{~s}$, the sun 
Fig. 11 Grid phase $A$ voltage and current, corresponding to MPPT activation point (upper graph), ramp (middle graph) and step (lower graph) changes of irradiation
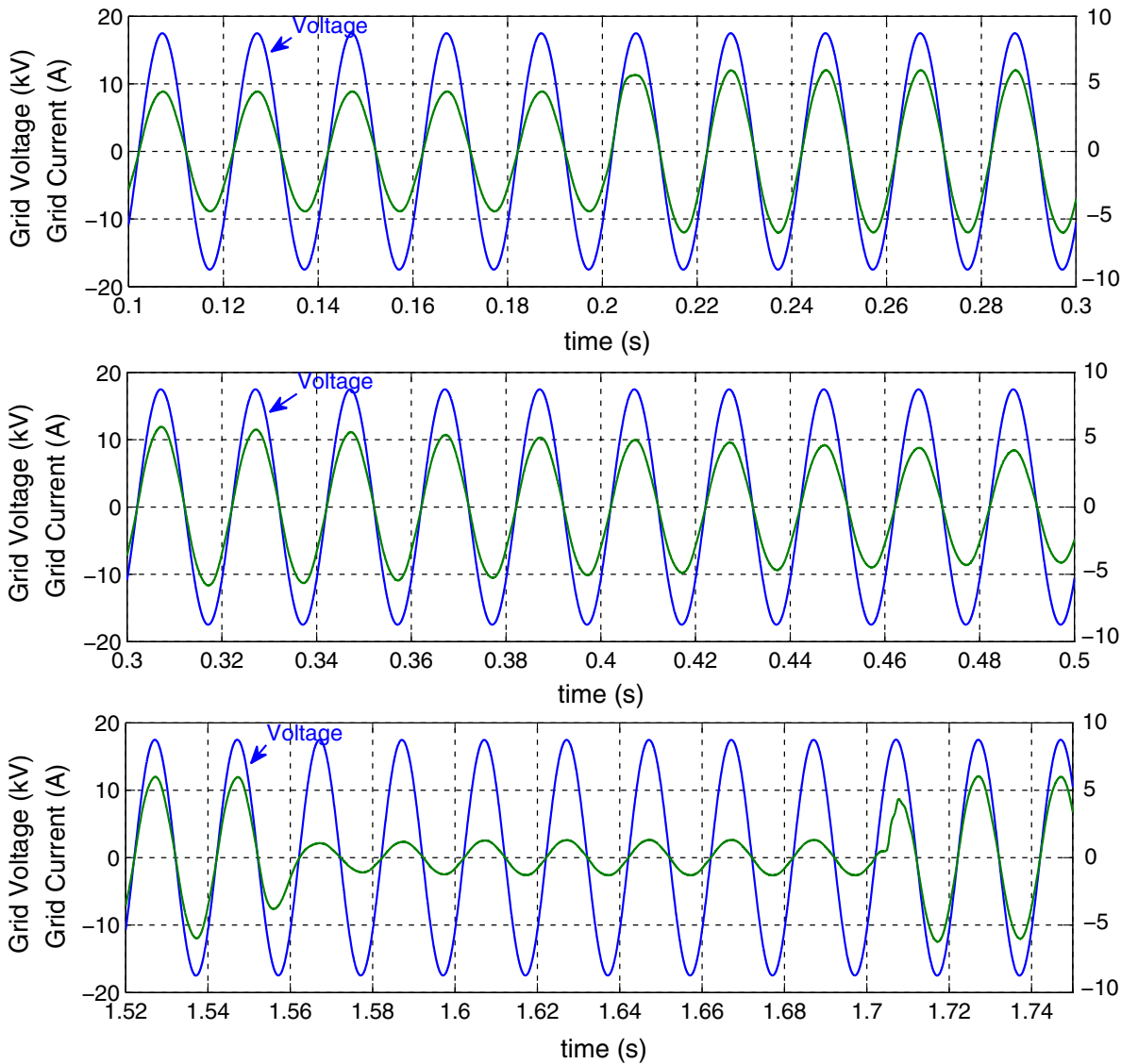

irradiance was decreased as a ramp to $250 \mathrm{~W} / \mathrm{m}^{2}$ in $0.5 \mathrm{~s}$. As shown in Fig. 9, $P V_{1}, P V_{2}$ and grid instantaneous active power $\left(P_{p v 1}, P_{p v 2}\right.$ and $\left.P_{G r i d}\right)$ follow the irradiation variation very close to the MPP. At the end of irradiation ramp down the PV arrays power and the grid power reach their steady state with $50 \mathrm{~ms}$ delay. PV arrays voltage were then dropped down to $345 \mathrm{~V}$ at $t=0.8 \mathrm{~s}$ for $P V_{1}$ and $P V_{2}$ arrays and were reached to $350 \mathrm{~V}$ in 100 milliseconds. At the steady state condition with $250 \mathrm{~W} / \mathrm{m}^{2}$ sun irradiance, output power to grid and total PV system produced power were 34.5 and $35.94 \mathrm{~kW}$, respectively, which resulted in $96 \%$ efficiency.

From $t=0.95 \mathrm{~s}$ to $t=1.45 \mathrm{~s}$, irradiation was ramped up again from 250 to $1000 \mathrm{~W} / \mathrm{m}^{2}$ which is shown in Fig. 10. It can be seen that MPPT controller have good performance tracking maximum power during solar irradiance changes.

In order to test the dynamic response of the MPPT controller against fast solar irradiance changes, step changes in $t=1.55 \mathrm{~s}$ and $t=1.7 \mathrm{~s}$ are applied and irradiance was changed about $750 \mathrm{~W} / \mathrm{m}^{2}$ in $10 \mathrm{~ms}$. PV arrays and grid power were settled to their steady state values in about $50 \mathrm{~ms}$ for step-down part, and $5 \mathrm{~ms}$ for step-up part, and $P V_{1}$ and $P V_{2}$ arrays voltage were dropped down to 310 and $305 \mathrm{~V}$, respectively in step-down part. Then PV arrays voltage were arrived to $350 \mathrm{~V}$ after 80 milliseconds.
It should be noted that DC-link voltage was regulated by VSC controller during all the above disturbances, as shown in the lower graph of Figs. 9 and 10. The achieved results show the satisfactory performance of the MPPT which has been performed by LLC resonant DC/DC converter.

Figure 11 shows voltage and current waveforms of grid phase $A$, while changing solar irradiance. The initial start up status of the PV system and the MPPT controller activation point are shown in the upper graph and the middle graph represents the ramp change and the lower graph shows the step changes of irradiation. As it can be seen from this figure, voltage and current are in phase which confirms unity PF provided by VSC controller.

In this study a high power 3-level NPC three-phase VSC was used to transform DC available power to AC power which has low harmonic distortion in output. As a result, the output filter amount and size will reduce and the injected current to the grid will be more sinusoidal. Fig. 12 shows the harmonic spectrum of grid phase $A$ current analyzed by fast fourier transform (FFT) on one cycle of fundamental frequency for different instants. As shown in this figure, total harmonic distortion is less than $2 \%$ in more distorted region of current which occurs at $250 \mathrm{~W} / \mathrm{m}^{2}$ sun irradiance. 
Fig. 12 FFT analysis and harmonic spectrum of the output phase current injected to grid at different instants
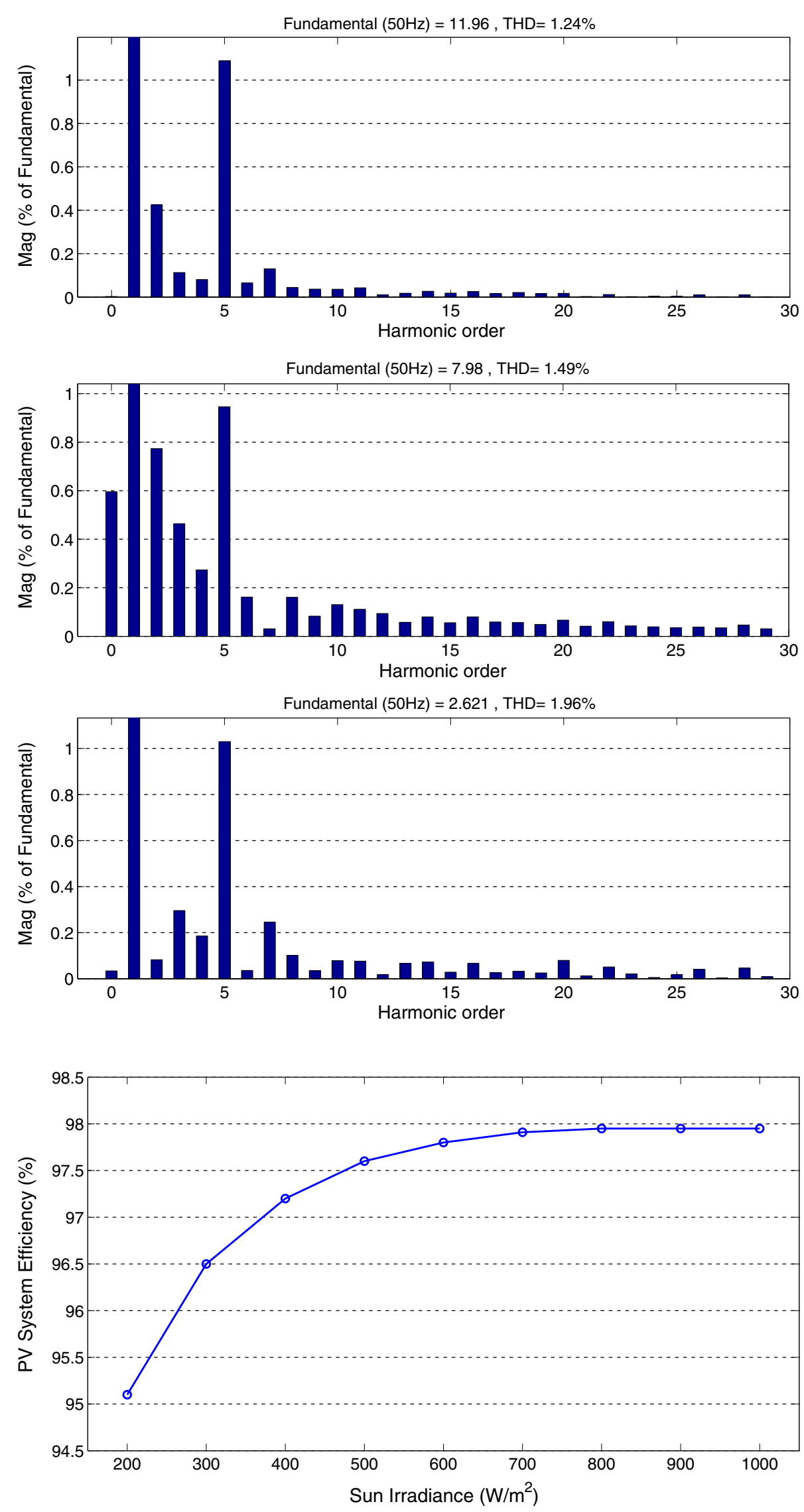

Fig. 13 Proposed PV system efficiency versus sun irradiance 
Table 3 Loss modeling for efficiency simulation

\begin{tabular}{lll}
\hline Component & Description & Value \\
\hline MOSFET & Drain-source on-resistance & $0.005 \mathrm{~m} \Omega$ \\
IGBT & Conductance voltage & $1.2 \mathrm{~V}$ \\
Diode & Forward voltage & $1 \mathrm{~V}$ \\
$R_{L r}$ & Internal resistance of $L_{r}$ & $1 \mathrm{~m} \Omega$ \\
\hline
\end{tabular}

The efficiency of proposed grid-connected PV system versus sun irradiance is shown in Fig. 13. In this figure the efficiency was considered as $\frac{P_{g}}{P_{P V}} \times 100$, regarding Fig. 1, and total produced PV power was varied between $17.5 \%$ of full load up to full load. In this simulation, component's loss model were considered as given in Table 3 .

\section{Conclusions}

This paper has presented an application of a full bridge LLC resonant DC/DC converter in a three-phase grid-connected PV system with multi string topology. For extracting the maximum power from the PV arrays, the InC based method integrated with PI controller has been proposed for LLC resonant DC/DC converter. The LLC converter has the benefit of zero voltage switching, which results in a higher switching frequency and higher efficiency in comparison with conventional boost converters used in numerous PV applications. Unlike the boost converter, the parasitic capacitance of the PV panels to ground in this type of converter does not impose any leakage current problem due to its intrinsic electric isolation. Regarding LLC converter's operation at high frequencies, the use of smaller and cost effective magnetic and filter components is possible, which results in lower EMI. Furthermore, DC-link capacitor which is used to store energy and acts as a fixed DC bus for the inverter could be chosen smaller thanks to the high switching frequency and fast dynamic response of the resonant converter. The proposed grid-connected PV system has a modular structure and can be easily extended to more PV strings and large scale PV plants just by paralleling the output of the resonant converters of each string. This modular feasibility has been demonstrated by considering two strings with different power ratings.

The inverter controller consists of the outer loop to keep the DC bus voltage constant, and the inner loop to synchronize the output voltage of the inverter with the grid voltage and also to keep the output current in phase with voltage.

The obtained results have confirmed the effectiveness of the system to provide and ensure appropriate power and unity PF to the grid, as well as DC-link voltage stability. The ability of the DC/DC resonant converter to extract maximum power from the solar arrays under rapid changing irradiance, has also demonstrated. The achieved results can be easily extended to a higher number of strings.

\section{References}

1. Wang, H., Zhang, D.: The stand-alone PV generation system with parallel battery charger. International Conference on Electrical and Control Engineering (ICECE, 2010), pp. 4450-4453, 25-27 June 2010

2. Shayani, R., de Oliveira, M.: A new index for absolute comparison of standalone photovoltaic systems installed at different locations. IEEE Trans. Sustain. Energy 2(4), 495-500 (2011)

3. Dash, P.P., Kazerani, M.: Dynamic modeling and performance analysis of a grid-connected current-source inverter-based photovoltaic system. IEEE Trans. Sustain. Energy 2(4), 443-450 (2011)

4. Bonfiglio, A., Brignone, M., Delfino, F., Procopio, R.: Optimal control and operation of grid-connected photovoltaic production units for voltage support in medium voltage networks. IEEE Trans. Sustain. Energy 5(1), 254-263 (2014)

5. Radwan, A.A.A.: Analysis and active suppression of AC- and DCside instabilities in grid-connected current-source converter-based photovoltaic system. IEEE Trans. Sustain. Energy 4(3), 630-642 (2013)

6. Mahmud, M.A.: Nonlinear current control scheme for a singlephase grid-connected photovoltaic system. IEEE Trans. Sustain. Energy 5(1), 218-227 (2014)

7. Kjaer, S.B., Pedersen, J.K., Blaabjerg, F.: A review of single-phase grid-connected inverters for photovoltaic modules. IEEE Trans. Ind. Appl. 41(5), 1292-1306 (2005)

8. Chien-Hsuan, C., En-Chih, C., Hung-Liang Cheng, C.: A highefficiency solar array simulator implemented by an LLC resonant DC-DC converter. IEEE Trans. Power Electron. 28(6), 3039-3046 (2013)

9. LaBella, T., Wensong, Y., Jih-Sheng, L., Senesky, M., Anderson, D.: A bidirectional-switch-based wide-input range high-efficiency isolated resonant converter for photovoltaic applications. IEEE Trans. Power Electron. 29(7), 3473-3484 (2014)

10. Jun-Young, L., Yu-Seok, J., Byung-Moon, H.: An isolated DC/DC converter using high-frequency unregulated LLC resonant converter for fuel cell applications. IEEE Trans. Ind. Electron. 58(7), 2926-2934 (2011)

11. Xinke, W., Guichao, H., Junming, Z., Zhaoming, Q.: A new currentdriven synchronous rectifier for series-parallel resonant (LLC) DC-DC converter. IEEE Trans. Ind. Electron. 58(1), 289-297 (2011)

12. Shih-Yu, C., Zhu Rong, L., Chen, C.L.: Analysis and design of single-stage AC/DC LLC resonant converter. IEEE Trans. Ind. Electron. 59(3), 1538-1544 (2012)

13. Subudhi, B., Pradhan, R.: A comparative study on maximum power point tracking techniques for photovoltaic power systems. IEEE Trans. Sustain. Energy 4(1), 89-98 (2013)

14. Chiang, S.J., Chang, K.T., Yen, C.Y.: Residential photovoltaic energy storage system. IEEE Trans. Ind. Electron. 45(3), 385-394 (1998)

15. Kaundinya, D.P., Balachandra, P., Ravindranath, N.H.: Gridconnected versus stand-alone energy systems for decentralized power: a review of literature. Renew. Sustain. Energy Rev. 13(8), 2041-2050 (2009)

16. Chee, W.T., Green, T.C., Carlos, A.H.-A.: Analysis of perturb and observe maximum power point tracking algorithm for photovoltaic applications. 2008 IEEE 2nd International Power and Energy Conference (PECon 2008), 2008 
17. Elgendy, M.A., Zahawi, B., Atkinson, D.J.: Assessment of perturb and observe MPPT algorithm implementation techniques for PV pumping applications. IEEE Trans. Sustain. Energy 3(1), 21-33 (2012)

18. Kollimalla, S.K.: Variable perturbation size adaptive P\&O MPPT algorithm for sudden changes in irradiance. IEEE Trans. Sustain. Energy 5(3), 718-728 (2014)

19. Elgendy, M.A., Zahawi, B., Atkinson, D.: Assessment of the incremental conductance maximum power point tracking algorithm. IEEE Trans. Sustain. Energy 4(1), 108-117 (2013)

20. Yan, Z., Fei, L., Jinjun, Y., Shanxu, D.: Study on realizing MPPT by improved incremental conductance method with variable step-size. In: Proceedings of the 3rd IEEE Conference on Industrial Electronics and Applications, (ICIEA 2008), pp. 547-550, Singapore, 3-5 June 2008 (2008)

21. Esram, T., Kimball, J.W., Krein, P.T., Chapman, P.L., Midya, P.: Dynamic maximum power point tracking of photovoltaic arrays using ripple correlation control. IEEE Trans. Power Electron. 21(5), 1282-1291 (2006)

22. Chen, Y., Smedley, K.: A cost-effective single-stage inverter with maximum power point tracking. IEEE Trans. Power Electron. 17(4), 1289-1294 (2002)

23. Fortunato, M., Giustiniani, A., Petrone, G., Spagnuolo, G., Vitelli, M.: Maximum power point tracking in a one-cycle-controlled single-stage photovoltaic inverter. IEEE Trans. Ind. Electron. 55(7), 2684-2693 (2008)

24. Chiu, C.S.: T-S fuzzy maximum power point tracking control of solar power generation systems. IEEE Trans. Energy Conv. 25(4), 1123-1132 (2010)

25. Al, A., Dhaouadi, R.: Efficiency optimization of a DSP based standalone PV system using fuzzy logic and dual- MPPT control. IEEE Trans. Ind. Inform. 8(3), 573-584 (2012)

26. Femia, N., Lisi, G., Petrone, G., Spagnuolo, G., Vitelli, M.: Distributed maximum power point tracking of photovoltaic arrays: novel approach and system analysis. IEEE Trans. Ind. Electron. 55(7), 261-2621 (2008)

27. Bianconi, E., Calvente, J., Giral, R., Mamarelis, E., Petrone, G., Ramos-Paja, C.A., Spagnuolo, G., Vitelli, M.: A fast current-based MPPT technique employing sliding mode control. IEEE Trans. Ind. Electron. 60(3), 1168-1178 (2013)

28. Bianconi, E., Calvente, J., Giral, R., Mamarelis, E., Petrone, G., Ramos-Paja, C.A., Spagnuolo, G., Vitelli, M.: Perturb and observe MPPT algorithm with a current controller based on the sliding mode. Int. J. Electr. Power Energy Syst. 44(1), 346-356 (2013)

29. Buccella, C., Cecati, C., Latafat, H.: Digital control of power converters: a survey. IEEE Trans. Ind. Inform. 8(3), 437-447 (2012)

30. Blaabjerg, F., Teodorescu, R., Liserre, M., Timbus, A.V.: Overview of control and grid synchronization for distributed power generation systems. IEEE Trans. Ind. Electron. 53(5), 1398-1409 (2006)

31. Zargari, N.R., Joos, G.: Performance investigation of a currentcontrolled voltage-regulated PWM rectifier in rotating and stationary frames. IEEE Trans. Ind. Electron. 42, 396-401 (1995)

32. Mastromauro, R.A., Liserre, M., Kerekes, T., Dell'Aquila, A.: A single-phase voltage-controlled grid-connected photovoltaic system with power quality conditioner functionality. IEEE Trans. Ind. Electron. 56(11), 4436-4444 (2009)

33. Libo, W., Zhengming, Z., Jianzheng, L.: A single-stage threephase grid-connected photovoltaic system with modified MPPT method and reactive power compensation. IEEE Trans. En. Conv. 22(4), 881-886 (2007)
34. Figueres, E., Garcera, G., Sandia, J., Gonzalez-Espin, F., Rubio, J.: Sensitivity study of the dynamics of three-phase photovoltaic inverters with an LCL grid filter. IEEE Trans. Ind. Electron. 56(3), 706-717 (2009)

35. Cavalcanti, M.C., de Oliveira, K.C., de Farias, A.M., Neves, F.A.S., Azevedo, G.M.S., Camboim, F.C.: Modulation techniques to eliminate leakage currents in transformerless three-phase photovoltaic systems. IEEE Trans. Ind. Electron. 58(4), 1360-1368 (2010)

36. Patrao, I., Figueres, E., González-Espín, F.: Transformerless topologies for grid-connected single-phase photovoltaic inverters. Renew. Sustain. Energy Rev. 15(7), 3343-3423 (2011)

37. Buccella, C., Cecati, C., Latafat, H., Razi, K.: Comparative transient response analysis of LLC resonant converter controlled by adaptive pid and fuzzy logic controllers. In: Proceedings of the IEEE International Conference IECON, pp. 4729-4734, 2012

38. Amorndechaphon, D., Premrudeepreechacharn, S., Higuchi, K.: An improved soft-switching single-phase inverter for small gridconnected PV-system. In: Proceedings of the IEEE International Conference IECON, pp. 2125-2130, 2008

39. Buccella, C., Cecati, C., Latafat, H., Razi, K.: A grid-connected PV system with LLC resonant DC-DC converter. 2013 International Conference on Clean Electrical Power (ICCEP), pp. 777-782, 1113 June 2013

40. de Brito, M.A.G., Galotto, L., Sampaio, L.P., de Azevedo e Melo, G., Canesin, C.A.: valuation of the main MPPT echniques for photovoltaic applications. IEEE Trans. Ind. Electron. 60(3), 11561167 (2013)

41. Chen, L., Amirahmadi, A., Zhang, Q., Kutkut, N., Batarseh, I.: Design and implementation of tree-phase two-stage grid-connected module integrated converter. IEEE Trans. Power Electron. 29(8), 3881-3892 (2014)

42. Kim, I.S., Kim, M.B., Youn, M.J.: New maximum power point tracker using sliding-mode observer for estimation of solar array current in the grid-connected photovoltaic system. IEEE Trans. Ind. Electron. 53(4), 1027-1035 (2006)

43. Sunpower datasheet. http://www.cleanfuelconnection.com/ solar-energy/brochures/e18-305.pdf (2010)

44. Perera, B.K., Pulikanti, S.R., Ciufo, P., Perera, S.: Simulation model of a grid-connected single-phase photovoltaic system in PSCAD/EMTDC. In: Proceedings of the IEEE International Conference POWERCON, pp. 1-6, 2012

45. Buccella, C., Cecati, C., Latafat, H., Razi, K.: Digital control of a half-bridge LLC resonant converter. In: Proceedings of the IEEE International Conference EPE-PEMC, pp. LS6a.4-1-LS6a.4-6, 2012

46. Buccella, C., Cecati, C., Latafat, H., Pepe, P., Razi, K.: Observerbased control of LLC DC/DC resonant converter using extended describing functions. IEEE Trans. Power Electron. 30(10), 58815891 (2015)

47. Lu, B., Liu, W., Liang, Y., Lee, F.C., van Wyk, J.D.: Optimal design methodology for LLC resonant converter. In: Proceedings of the IEEE Applied Power Electronics Conference and Exposition, pp. 533-538, 2006

48. Matlab 7.13 (R2011b) Software Package. http://www.Mathworks. com 